\title{
Experimental characterisation of macro fibre composites and monolithic piezoelectric transducers for strain energy harvesting
}

\author{
Michele Pozzi ${ }^{*}$, Alfredo Canziani, Isidro Durazo-Cardenas, Meiling Zhu \\ School of Applied Sciences \\ Cranfield University, Bedfordshire, MK43 0AL, UK \\ *e-mail: m.pozzi@cranfield.ac.uk (Corresponding author)
}

\begin{abstract}
Compact and lightweight energy harvesters are needed to power wireless sensor nodes (WSNs). WSNs can provide health monitoring of aircraft structures, improving safety and reducing costs by enabling predictive maintenance. A simple solution, which meets the requirements for lightness and compactness, is represented by piezoelectric generators fixed to the surface of the wing (i.e. the wing skin). Such piezoelectric patches can harvest the strain energy available when the wing is flexed, as occurs, for example, in the presence of gust loading. For this study, monolithic piezoelectric sheets and macro fibre composite (MFC) generators were fixed to plates made of two materials commonly used for aircraft wing skin: Al-2024 aluminium alloy and an epoxy-carbon fibre composite. The plates then underwent harmonically varying loading in a tensile testing machine. The power generation of the harvesters was measured at a selection of strain levels and low excitation frequencies, across a range of electrical loads. The optimal electrical load, yielding maximum power extraction, was identified for each working condition. The generated power increases quadratically with the strain and linearly with the frequency. The optimal electrical load decreases with increasing frequency and is only marginally dependent on strain. Absolute values of generated power were highest with the MFC, reaching $12 \mathrm{~mW}\left(330 \mu \mathrm{W} / \mathrm{cm}^{2}\right)$ under $1170 \mu$ strain peak-to-peak excitation at $10 \mathrm{~Hz}$ with a $66 \mathrm{k} \Omega$ load. Power generation densities of $600 \mu \mathrm{W} / \mathrm{cm}^{2}$ were achieved under $940 \mu$ strain with the monolithic transducers at $10 \mathrm{~Hz}$. It is found that MFCs have a lower power density than monolithic transducers, but, being more resilient, could be a more reliable choice. The power generated and the voltage outputs are appropriate for the intended application.
\end{abstract}

Keywords: energy harvesting, structural health monitoring, piezoelectric generator, strain energy harvesting, macro fibre composite, MFC

\section{INTRODUCTION}

A significant cost incurred in the operation of an airline fleet is maintenance. A general trend seen across all areas of through-life service engineering is a shift from unscheduled corrective maintenance, carried out in response to a fault, and fixed-schedule maintenance, where each part is replaced periodically based on its typical life span, to on-condition maintenance, where the condition of a component is assessed to permit intervention before it will develop a fault, as many modes of failure do show early warning signs ${ }^{1}$. More recently, a new form of maintenance has attracted interest: 
predictive maintenance, facilitated by fixed instrumentation or built-in sensory equipment capable of continuously monitoring the conditions of critical components and even automatically report when a given threshold of wear is exceeded. This information is combined with expert knowledge and past history to assess the health status of the subsystem and schedule a maintenance action, also taking into account operational requirements ${ }^{2}$. Structural Health Monitoring (SHM) systems for aircraft are designed to monitor and report on the conditions of vital components, such as wings and landing gear. A significant obstacle to the widespread adoption of SHM systems, particularly in the aeronautic sector, is represented by the additional weight and complexity introduced by the wires needed to supply power and relay the collected data. The natural solution to this problem is the adoption of wireless sensor nodes (WSNs), i.e. intelligent sensors capable of collecting the data and transmitting them wirelessly to a central hub on the aircraft. Some WSNs also carry the promise of being retrofittable to existing aircraft.

If the energy requirements of WSNs were met with replaceable or rechargeable batteries, the maintenance issue would simply be shifted to scheduled battery replacement, with associated operational stops. It is therefore necessary to design self-powered WSNs, taking advantage of energy harvesting technologies. Piezoelectric materials can convert strain energy into electrical energy. The main advantages of harvesters based on the piezoelectric effect reside in their compactness, lightweight and absence of moving parts, yielding the low-profile, low added weight and reliability which are required by the aeronautic industry.

With a view to develop self-powered wireless structural health monitoring systems, the work reported here is centred on patch-like piezoelectric energy harvesters which can be attached to the wing skin to directly convert mechanical strain into electrical energy. A similar device was presented by Churchill et al. ${ }^{3}:$ a $17 \mathrm{~cm}^{2}$ harvester of piezoelectric fibres tested under harmonic excitation of frequencies between 60 and $180 \mathrm{~Hz}$ generated up to almost $0.8 \mathrm{~mW}$ with a strain of $3 \cdot 10^{-4}$ (i.e. $300 \mu$ strain). In the work reported in this paper, piezoelectric devices were fixed to Al-2024 aluminium alloy sheets and also to aeronautic grade composite material sheets. We focus on lower excitation frequencies (2.5 to $10 \mathrm{~Hz})$ as these, by covering the range of resonance frequencies found in most common aircraft wings, are more representative of real world conditions for harvesters fixed to a wing skin. Experiments show that up to $12 \mathrm{~mW}$ of power can be generated under a strain of $1170 \mu$ strain at $10 \mathrm{~Hz}$ by MFC devices. Bulk PZT material in the form of thin sheets was also tested and showed higher energy densities per unit area. The paper presents comprehensive data on the power generation performance of this kind of harvesters as well as the effective electrical parameters of the tested piezoelectric devices in this operational mode. Hence, the paper can be used to support the design of a self-powered SHM system (device selection, sizing, power management circuit design, etc.).

\section{EXPERIMENTAL DETAILS}

MFC devices type M8528-P2 were sourced from Smart Material GmbH. The M8528-P2 devices operate in the $\mathrm{d}_{31}$ mode and have an active area of $85 \times 28 \mathrm{~mm}^{2}$; full details can be found in the manufacturer datasheet ${ }^{4}$. PZT monolithic devices were kindly supplied by Jingdezhen Tonphin Electrical Co., Ltd (China). Two samples were tested: a "large" sheet $\left(20 \times 20 \mathrm{~mm}^{2}\right)$ and a "small" one $\left(10 \times 10 \mathrm{~mm}^{2}\right)$; both have a thickness of approximately $190 \mu \mathrm{m}$. Two substrate materials were studied: a $3 \mathrm{~mm}$ thick sheet of aerospace grade aluminium alloy ( $\mathrm{Al} 2024$ ) and a $4 \mathrm{~mm}$ thick, 16-ply composite made with HexPly ${ }^{\circledR}$ M21 having layout [45/-45]n. Both substrates were $210 \mathrm{~mm}$ wide and $300 \mathrm{~mm}$ long; the composite sheet was reinforced in the grip areas with two pairs of Al plates glued to it. The piezoelectric devices were bonded in the 
vertical centre of the substrates with 3M's DP460 structural epoxy adhesive: after lightly sanding the substrate surface with fine emery paper and cleaning with isopropyl alcohol, a thin layer $(\sim 30 \mu \mathrm{m})$ of adhesive was spread on it; the devices were then laid over the adhesive and a compressive pressure of about $400 \mathrm{kPa}$ was applied and maintained for approximately 20 hours at room temperature; finally, the pressure was removed and a final treatment of 2 hours at $65^{\circ} \mathrm{C}$ was performed.

The substrates with bonded piezoelectric devices were mounted in a 500kN Instron tensile testing machine and subjected to cyclic loading of the form $F=F_{p r e}+F_{0} \sin (2 \pi f t)$, so as to achieve the specified strain levels, measured with a strain gauge mounted near the devices. Note that $F_{\text {pre }}$ was chosen so that the substrates were always in tension during testing. The frequencies investigated were $2.5,5,7.5$ and $10 \mathrm{~Hz}$, for strain levels ranging approximately between 200 and $1000 \mu$ strain peak-to-peak.

The electrical output was measured in the form of the voltage developed across a resistor connected to the energy harvester. The voltage was measured by an Agilent 34401A interfaced to a computer running an ad-hoc Labview VI that recorded the data at a rate of $1 \mathrm{kHz}$. Harvested power was then calculated in MATLAB by numerically averaging the instantaneous power $\left(P\left(t_{i}\right)=V^{2}\left(t_{i}\right) / R\right.$ ) over 5 seconds. In all calculations, the internal resistance of the multimeter was taken into account to deduce the real electrical load connected to the harvester.

\section{RESULTS AND DISCUSSION}

\subsection{MFC ON AL ALLOY SUBSTRATE}

The Al-2024 alloy substrate with MFC bonded on it was tested with peak-to-peak strain levels of 480, 710, 940 and $1170 \mu$ strain; each strain level was applied at $2.5,5,7.5$ and $10 \mathrm{~Hz}$. The root-mean-square power, voltage and current for the lowest and highest strain level are reported in Figure 1. The voltage vs. load curves exhibit a monotonic growth towards an asymptotic value (the open circuit voltage), with the approach being faster at higher frequencies. The measured output voltage is within very useful and directly usable values: at the Maximum Power Points (MPPs) they are around $12 \mathrm{~V}$ at all frequencies for the lowest strain and $28 \mathrm{~V}$ for the highest strain. The current vs. load curves start at a high value and decrease monotonically, staying in any case above $40 \mu \mathrm{A}$ (lowest strain) or above $100 \mu \mathrm{A}$ (highest strain). The power vs. load curves show the characteristic behaviour seen in impedance matching measurements on piezoelectric harvesters: the power extracted from the harvester rapidly increases with the load until the MPP is reached, then it starts to decrease slowly. According to the Maximum Power Transfer theorem, the power extracted from the harvester is maximum when its impedance is equal to the complex conjugate of the load's impedance. When this occurs, the impedance is said to be matched and the extracted power is:

$$
P=\frac{1}{2} V_{o c}^{2} \frac{R_{L}}{\left(R_{h}+R_{L}\right)^{2}+\left(1 /\left(\omega C_{h}\right)\right)^{2}}
$$

where $V_{o c}$ is the open-circuit voltage of the harvester, $R_{h}$ and $C_{h}$ its resistance and capacitance, $R_{L}$ is the resistance of the external load (in this expression we have assumed that the complex part of the load's impedance be negligible). The experimental data of power vs. electrical load, some of which are plotted in Figure 1, have been used to perform a non- 
linear fitting of Equation 1. The resulting parameters are listed in Table 1 together with the corresponding Maximum Power Points (MPPs). Comparison between results at the same frequency shows that the voltage generated at the MPPs is approximately linear with the strain applied, whilst the power is proportional to the square of the strain applied. Observing the electrical loads for which the Maximum Power Points are found ( $\mathrm{R}_{\mathrm{MPP}}$ in Table 1), it is easy to see a strong dependence on the frequency and a less pronounced dependence on the strain level. The former is an inverse relationship and is due to the effect of the angular frequency of the mechanical cycles $(\omega)$ on the impedance $Z_{h}$ of the harvester, which at these very low frequencies behaves much like a capacitor (of capacitance $C_{h}$ ):

$$
Z_{h} \approx \frac{1}{i \omega C_{h}} \text {, }
$$

as the real part and the inductance part are much smaller.
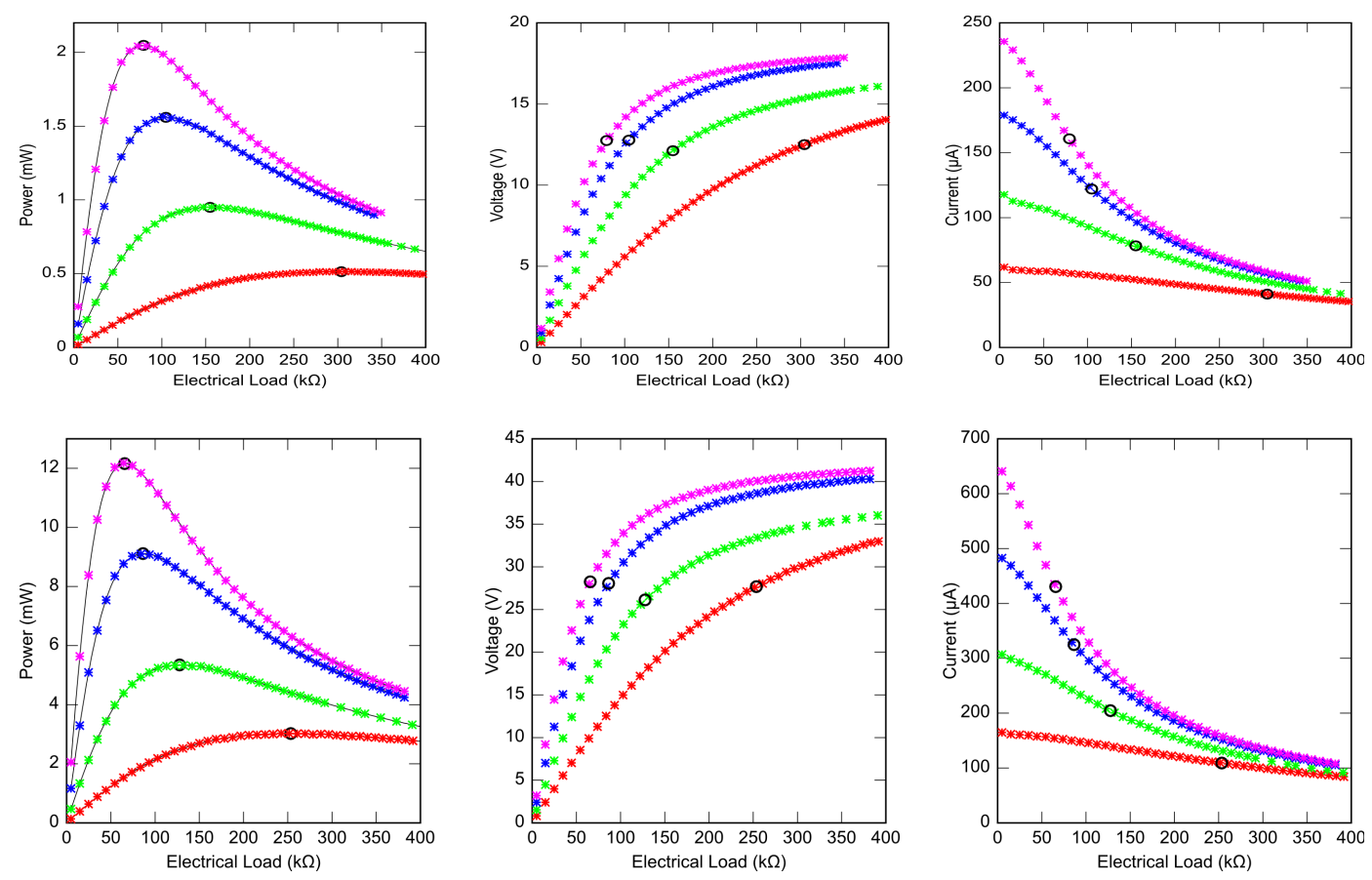

Figure 1. Root-mean-square voltage, current and power output as a function of the electrical load for the MFC bonded to the Al alloy substrate under a peak-to-peak strain of $480 \mu$ strain (above) and $1170 \mu$ strain (below). The circles indicate the MPPs; the continuous lines on the power graph are the result of the fitting. In every graph, the excitation frequency is $2.5,5,7.5$ and $10 \mathrm{~Hz}$ from bottom to top curve.

The minor dependence of $\mathrm{R}_{\mathrm{MPP}}$ on the strain is not explained by the linear theory of piezoelectricity, and could be due to a more complex material response. The voltage at the maximum power points and the open-circuit voltage are essentially dependent only on the strain level and not the frequency; this is an immediate consequence of one of the constitutive equations of piezoelectricity, relating the electric field $(E)$ to the strain $(S)$ via the coupling constant $q$ :

$$
E=-q S+\varepsilon_{S}^{-1} D
$$

where, additionally, $\varepsilon_{S}$ is the dielectric constant at fixed strain and $D$ is the electric displacement field. 
Current and power, on the contrary, increase both with frequency and strain. The former can be seen as a consequence of a stable voltage $(V)$ and decreasing electrical load $(R)$, as $I=V / R$ and $P=V^{2}{ }_{\mathrm{rms}} / R$. Another legitimate interpretation is based on the fact that the amount of electrical charges produced depends on the strain and is approximately the same at every cycle, which implies that the current and power are linearly related to the frequency. The dependence of $I_{r m s}$ and $P$ on the strain is a direct consequence of the same dependence being observed in the rms voltage.

Table 1. Results of fitting Equation 1 to the experimental results for each tested combination of strain and frequency on the MFC on Al-2024: electrical load, transferred power, voltage and current at the MPP; predicted open-circuit voltage; real component of harvester's impedance $\left(R_{h}\right)$ and its capacitance $\left(C_{h}\right)$.

Fitting parameters are given with a $95 \%$ confidence level.

\begin{tabular}{|c|c|c|c|c|c|c|c|c|}
\hline $\begin{array}{l}\text { Strain }_{p-p} \\
(\mu \text { strain) }\end{array}$ & $\begin{array}{l}\text { Freq. } \\
(\mathrm{Hz})\end{array}$ & $\begin{array}{l}\mathbf{R}_{\mathrm{MPP}} \\
(\mathbf{k} \boldsymbol{\Omega})\end{array}$ & $\begin{array}{c}\mathbf{P}_{\mathrm{MPP}} \\
(\mathrm{mW})\end{array}$ & $\begin{array}{l}\mathbf{V}_{\mathrm{MPP}} \\
\left(\mathrm{V}_{\mathrm{rms}}\right)\end{array}$ & $\begin{array}{c}\mathbf{I}_{\mathrm{MPP}} \\
\left(\boldsymbol{\mu} \mathbf{A}_{\mathrm{rms}}\right)\end{array}$ & $\begin{array}{c}\mathbf{V}_{\text {oc }} \\
\left(\mathbf{V}_{\mathrm{rms}}\right)\end{array}$ & $\begin{array}{c}\mathbf{R}_{\mathrm{h}} \\
(\mathrm{k} \boldsymbol{\Omega})\end{array}$ & $\begin{array}{c}\mathrm{C}_{\mathrm{h}} \\
(\mathrm{nF})\end{array}$ \\
\hline 480 & 2.5 & 304 & 0.51 & 12.5 & 41 & $25.8 \pm 0.2$ & $20.4 \pm 3$ & $210 \pm 0.7$ \\
\hline 480 & 5 & 155 & 0.95 & 12.1 & 78 & $24.9 \pm 0.1$ & $8.6 \pm 1$ & $205 \pm 0.4$ \\
\hline 480 & 7.5 & 105 & 1.56 & 12.8 & 122 & $26.3 \pm 0.1$ & $7.0 \pm 0.6$ & $204 \pm 0.4$ \\
\hline 480 & 10 & 79 & 2.05 & 12.7 & 161 & $26.3 \pm 0.1$ & $5.8 \pm 0.3$ & $203 \pm 0.4$ \\
\hline 710 & 2.5 & 284 & 1.13 & 17.9 & 63 & $37.6 \pm 0.2$ & $26.9 \pm 3$ & $225 \pm 0.6$ \\
\hline 710 & 5 & 144 & 2.11 & 17.4 & 121 & $36.2 \pm 0.1$ & $11.6 \pm 1$ & $222 \pm 0.4$ \\
\hline 710 & 7.5 & 98 & 3.43 & 18.3 & 187 & $38.2 \pm 0.1$ & $9.1 \pm 0.6$ & $218 \pm 0.5$ \\
\hline 710 & 10 & 74 & 4.52 & 18.3 & 247 & $38.3 \pm 0.1$ & $7.3 \pm 0.6$ & $217 \pm 0.8$ \\
\hline 940 & 2.5 & 268 & 1.97 & 23.0 & 86 & $48.3 \pm 0.3$ & $28.2 \pm 3$ & $239 \pm 0.6$ \\
\hline 940 & 5 & 136 & 3.68 & 22.4 & 164 & $47.1 \pm 0.1$ & $15.0 \pm 1$ & $236 \pm 0.5$ \\
\hline 940 & 7.5 & 93 & 5.96 & 23.5 & 253 & $49.6 \pm 0.1$ & $10.9 \pm 0.5$ & $232 \pm 0.5$ \\
\hline 940 & 10 & 70 & 7.92 & 23.5 & 336 & $49.7 \pm 0.1$ & $8.2 \pm 0.3$ & $230 \pm 0.5$ \\
\hline 1170 & 2.5 & 253 & 3.02 & 27.7 & 109 & $58.8 \pm 0.3$ & $32.5 \pm 3$ & $254 \pm 0.6$ \\
\hline 1170 & 5 & 128 & 5.35 & 26.1 & 205 & $55.5 \pm 0.2$ & $15.3 \pm 0.9$ & $249 \pm 0.6$ \\
\hline 1170 & 7.5 & 86 & 9.11 & 28.1 & 325 & $60.2 \pm 0.1$ & $12.0 \pm 0.5$ & $246 \pm 0.6$ \\
\hline 1170 & 10 & 66 & 12.16 & 28.2 & 430 & $60.5 \pm 0.1$ & $9.4 \pm 0.3$ & $244 \pm 0.5$ \\
\hline
\end{tabular}

\subsection{PZT SHEET ON AL ALLOY SUBSTRATE}

Figure 2 presents a selection of results from the large PZT sheet mounted on the Al-2024 alloy substrate. Qualitatively, these graphs are like those presented earlier for the MFC harvester. However, the range of electrical loads explored extends to larger values, as the capacitance of the device is lower, and the range of strain applied was lower to ensure the preservation of the integrity of the PZT devices. As previously highlighted for the MFC, also in this case voltages are of very useful values, at around $5 \mathrm{~V}$. The power produced reaches a maximum of $100 \mu \mathrm{W}$ at $250 \mu$ strain $(10 \mathrm{~Hz})$. Table 2 summarises the locations of the Maximum Power Points (electrical loads at which the MPPs occur), the corresponding electrical outputs (voltage, current and power) and the parameters derived from the nonlinear fitting of Equation 1 to the data. General dependence on strain and frequency are similar to what was described above for the MFC harvester. 
It is worthwhile to note that the large values of electrical load needed for optimal power transfer are due to the relatively small size of the PZT sheet (only $4 \mathrm{~cm}^{2}$ ): as the capacitance is approximately linear with the area, the matching impedance $R_{L}$ decreases rather rapidly with the linear dimensions of the device, hence a real-life harvester would not present such a large output impedance.
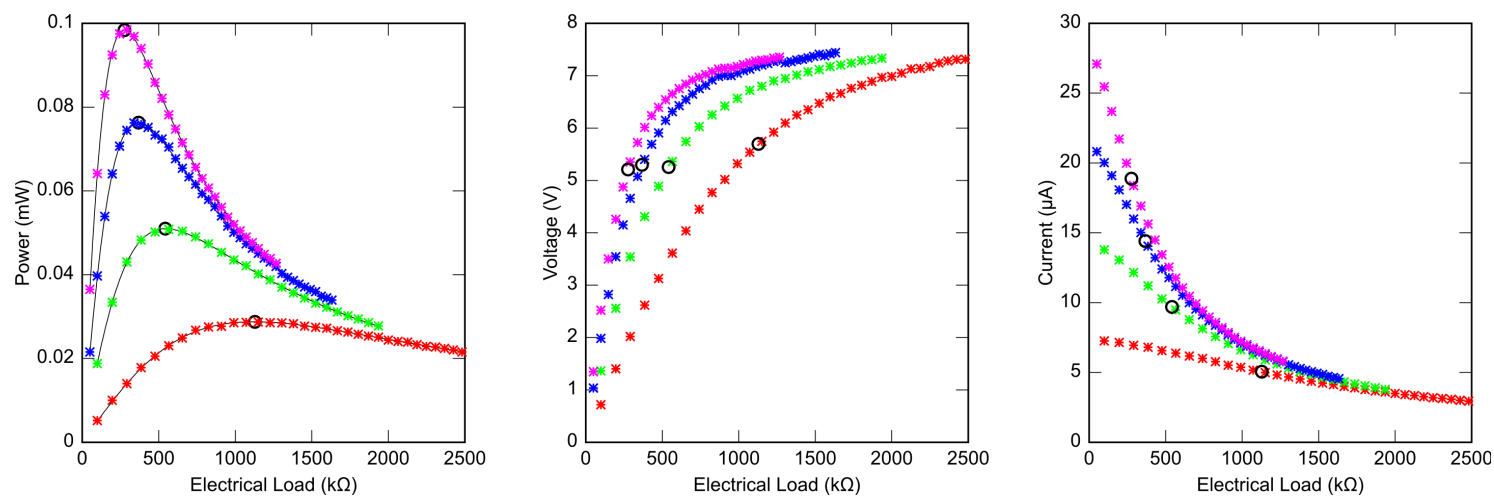

Figure 2. Root-mean-square power, voltage and current output as a function of the electrical load for the large PZT sheet bonded to the Al-2024 alloy substrate under a peak-to-peak strain of $250 \mu$ strain. The circles indicate the MPPs; the continuous lines on the power graph are the result of the fitting. In every graph, the excitation frequency is $2.5,5,7.5$ and $10 \mathrm{~Hz}$ from bottom to top curve.

Table 2. Results of fitting Equation 1 to the experimental results for each tested combination of strain and frequency on the large PZT sheet on Al-2024: electrical load, transferred power, voltage and current at the MPP; predicted opencircuit voltage; real component of harvester's impedance $\left(R_{h}\right)$ and its capacitance $\left(C_{h}\right)$.

Fitting parameters are given with a $95 \%$ confidence level.

\begin{tabular}{|c|c|c|c|c|c|c|c|c|}
\hline $\begin{array}{l}\text { Strain }_{p-p} \\
\text { ( } \mu \text { strain) }\end{array}$ & $\begin{array}{r}\text { Freq. } \\
(\mathrm{Hz})\end{array}$ & $\begin{array}{l}\mathbf{R}_{\mathrm{MPP}} \\
(\mathrm{k} \Omega)\end{array}$ & $\begin{array}{c}\mathbf{P}_{\mathrm{MPP}} \\
(\mathbf{m W})\end{array}$ & $\begin{array}{c}V_{\text {MPP }} \\
\left(V_{\text {rms }}\right)\end{array}$ & $\begin{array}{c}\mathbf{I}_{\mathrm{MPP}} \\
\left(\boldsymbol{\mu} \mathbf{A}_{\mathrm{rms}}\right)\end{array}$ & $\begin{array}{c}V_{\text {oc }} \\
\text { (Vrms) }\end{array}$ & $\begin{array}{c}\mathbf{R}_{\mathrm{h}} \\
(\mathrm{k} \Omega)\end{array}$ & $\begin{array}{c}\mathbf{C}_{\mathbf{h}} \\
(\mathbf{n F})\end{array}$ \\
\hline 250 & 2.5 & 1128 & 0.03 & 5.7 & 5 & $11.4 \pm 0.1$ & $2 \pm 22$ & $56.7 \pm 0.3$ \\
\hline 250 & 5 & 542 & 0.05 & 5.3 & 10 & $11.0 \pm 0.1$ & $47.1 \pm 7$ & $58.5 \pm 0.3$ \\
\hline 250 & 7.5 & 368 & 0.08 & 5.3 & 14 & $10.9 \pm 0.1$ & $21.6 \pm 5$ & $58.1 \pm 0.3$ \\
\hline 250 & 10 & 276 & 0.10 & 5.2 & 19 & $10.8 \pm 0.1$ & $18.8 \pm 3$ & $58.0 \pm 0.3$ \\
\hline 480 & 2.5 & 980 & 0.13 & 11.3 & 11 & $24.6 \pm 0.5$ & $185 \pm 40$ & $66.0 \pm 0.5$ \\
\hline 480 & 5 & 489 & 0.26 & 11.3 & 23 & $23.7 \pm 0.2$ & $48.8 \pm 9$ & $65.5 \pm 0.3$ \\
\hline 480 & 7.5 & 327 & 0.39 & 11.3 & 34 & $23.3 \pm 0.2$ & $21.9 \pm 4$ & $64.9 \pm 0.2$ \\
\hline 480 & 10 & 249 & 0.51 & 11.3 & 45 & $23.3 \pm 0.1$ & $17.3 \pm 2$ & $64.2 \pm 0.1$ \\
\hline 710 & 2.5 & 844 & 0.36 & 17.4 & 21 & $34 \pm 1$ & $52 \pm 50$ & $76 \pm 2$ \\
\hline 710 & 5 & 445 & 0.69 & 17.6 & 39 & $36.3 \pm 0.4$ & $30.4 \pm 8$ & $71.8 \pm 0.5$ \\
\hline 710 & 7.5 & 304 & 1.03 & 17.7 & 58 & $36.8 \pm 0.3$ & $23.2 \pm 4$ & $70.1 \pm 0.3$ \\
\hline 710 & 10 & 229 & 1.37 & 17.7 & 77 & $36.7 \pm 0.3$ & $16.2 \pm 3$ & $69.6 \pm 0.3$ \\
\hline 940 & 2.5 & 819 & 0.61 & 22.3 & 27 & $46 \pm 1$ & $60 \pm 34$ & $78.2 \pm 0.8$ \\
\hline 940 & 5 & 415 & 1.19 & 22.2 & 54 & $46.2 \pm 0.4$ & $32.6 \pm 6$ & $76.9 \pm 0.4$ \\
\hline 940 & 7.5 & 284 & 1.77 & 22.4 & 79 & $47.0 \pm 0.5$ & $28.3 \pm 5$ & $75.4 \pm 0.4$ \\
\hline 940 & 10 & 215 & 2.36 & 22.5 & 105 & $47.4 \pm 0.5$ & $23.2 \pm 4$ & $74.4 \pm 0.4$ \\
\hline
\end{tabular}




\subsection{POWER DENSITY}

The power output measurements from the MFC, large PZT and small PZT harvesters are summarised in Figure 3 in terms of power per unit area of active device surface. Several important pieces of information are contained in the figure. First of all, the parabolic fits show that the power output is well predicted by a quadratic law between power and strain, as discussed above. Also, power from a given device at a given strain is linearly proportional to the frequency, as graphically indicated by the fact that data points for a given device are approximately equally spaced in the vertical direction, along which the cycling frequency increases. Further, we observe that the power density is significantly higher for the PZT harvesters than the MFC harvester. This stems from geometrical differences (at $190 \mu \mathrm{m}$, the active PZT material is thicker in the bulk PZT sheets than in the MFC, whose fibres are $180 \mu \mathrm{m}$-thick; also, the MFC's fibres cover only about $86 \%$ of the active area because of the gap between them), differences in material properties and the loss in strain coupling due to the kapton encapsulating the MFC. Finally, the large bulk PZT harvester has higher power density than the smaller one. One reason for this is the fact that the device edges are subject to lower strain than the middle regions, hence they produce less power ${ }^{5}$. Naturally, this loss of efficiency caused by the edges is less important for larger devices, for which the area to perimeter ratio is larger.

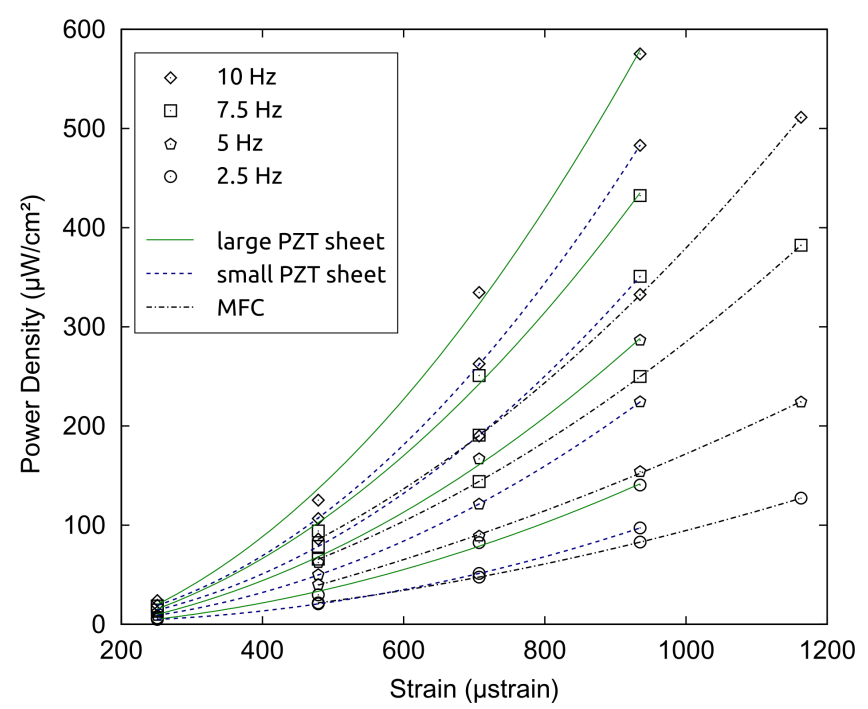

Figure 3. Comparison of the power densities obtained from the devices tested on the Al alloy substrate, plotted versus peak-to-peak strain. 

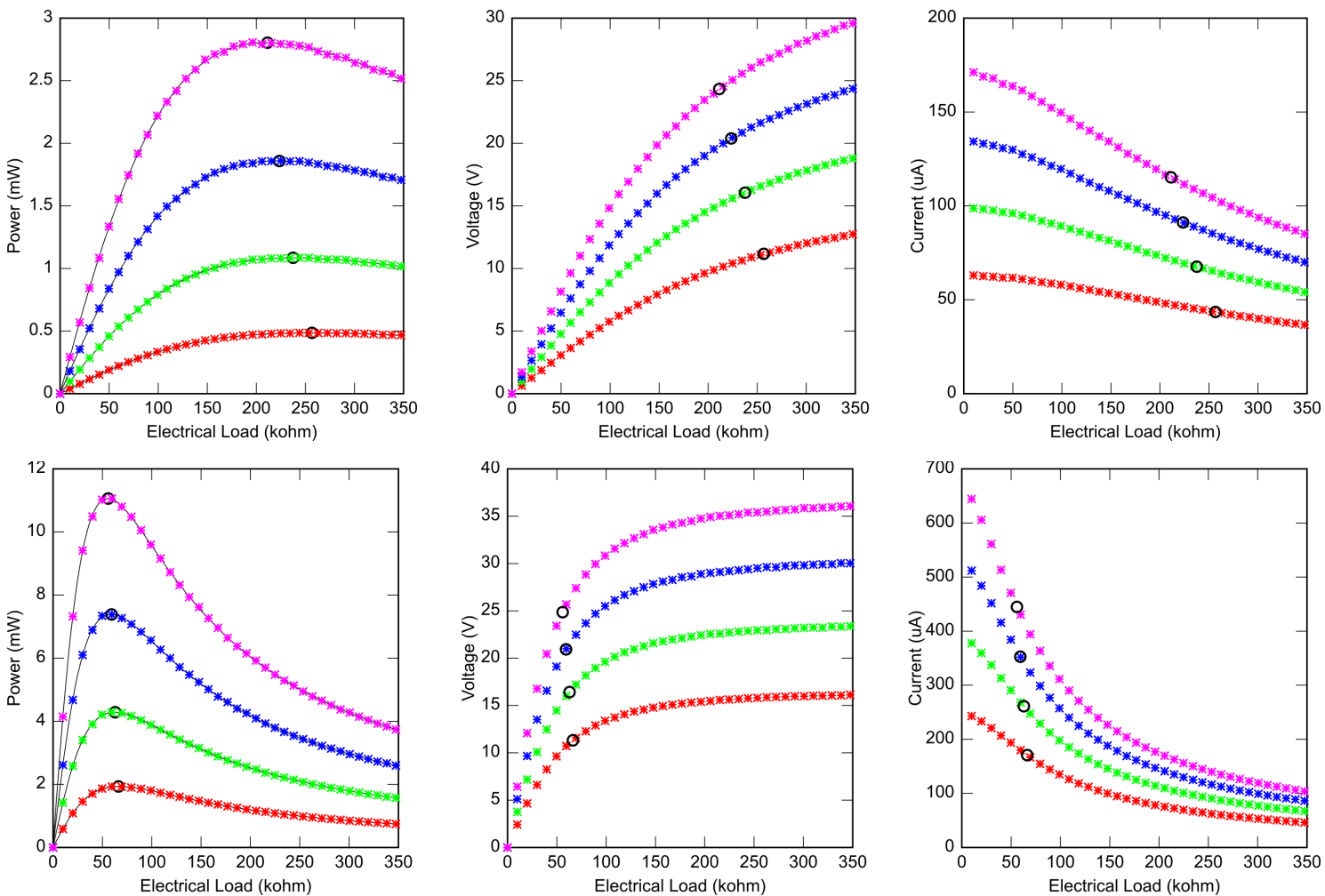

Figure 4. Root-mean-square power, voltage and current output as a function of the electrical load for the MFC device sheet to the composite substrate when excited at $2.5 \mathrm{~Hz}$ (above) and $10 \mathrm{~Hz}$ (below). The circles indicate the MPPs; the continuous lines on the power graph are the result of the fitting. In every graph, the strain levels are 440, 630, 830 and 1020 $\mu$ strain from bottom to top curve.

\subsection{MFC ON COMPOSITE SUBSTRATE}

As plots of the electrical quantities at constant strain for the MFC fixed to the composite substrate are qualitatively identical to those already presented for the Al-2024 alloy sheet, Figure 4 collects the rms power, voltage and current acquired at $2.5 \mathrm{~Hz}$ and $10 \mathrm{~Hz}$ with the curves in each plot acquired at different strain levels. From these graphs it is easy to visually see that the dependence of the electrical load at the MPP on strain is limited, although a slight decrease with increasing strain level is noticeable at the lowest frequency.

The Maximum Power Points for the MFC on composite were derived by fitting Equation 1 to the experimental data; the results are tabulated in Table 3. A direct comparison between Table 1 and Table 3 shows that higher power outputs were found on Al-2024 alloy. However, if we consider the fact that the strain levels were about 10\% higher in that case, and therefore we rescale the data in Table 3 remembering that the relationship between power and strain is approximately quadratic, we find that more power was harvested from the MFC on composite. The reason for this could be intrinsic in the properties of the substrate, as the directionality of the surface layer in the composite affects the strain transmitted to the attached harvester; however it is also possible that the thickness of the glue was not exactly the same in the two samples prepared, as modelling results indicate that the adhesive thickness has an important effect on the coupling between harvester and substrate, and therefore on the power generated ${ }^{5}$. 
Table 3. Results of fitting Equation 1 to the experimental results for each tested combination of strain and frequency on the MFC on the composite substrate: electrical load, transferred power, voltage and current at the MPP; predicted open-circuit voltage; real component of harvester's impedance $\left(R_{h}\right)$ and its capacitance $\left(C_{h}\right)$.

Fitting parameters are given with a $95 \%$ confidence level.

\begin{tabular}{|c|c|c|c|c|c|c|c|c|}
\hline $\begin{array}{l}\text { Strain }_{p-p} \\
\text { ( } \mu \text { strain) }\end{array}$ & $\begin{array}{l}\text { Freq. } \\
(\mathrm{Hz})\end{array}$ & $\begin{array}{l}\mathbf{R}_{\mathrm{MPP}} \\
(\mathrm{k} \Omega)\end{array}$ & $\begin{array}{c}\mathbf{P}_{\mathrm{MPP}} \\
(\mathrm{mW})\end{array}$ & $\begin{array}{c}\mathbf{V}_{\mathrm{MPP}} \\
\left(\mathbf{V}_{\mathrm{rms}}\right)\end{array}$ & $\begin{array}{c}\mathbf{I}_{\mathrm{MPP}} \\
\left(\boldsymbol{\mu} \mathbf{A}_{\mathrm{rms}}\right)\end{array}$ & $\begin{array}{c}V_{\text {oc }} \\
(\text { Vrms })\end{array}$ & $\begin{array}{c}\mathbf{R}_{\mathrm{h}} \\
(\mathrm{k} \Omega)\end{array}$ & $\begin{array}{c}\mathrm{C}_{\mathrm{h}} \\
(\mathrm{nF})\end{array}$ \\
\hline 440 & 2.5 & 257 & 0.49 & 11.2 & 44 & $23.0 \pm 0.2$ & $15.5 \pm 3$ & $248 \pm 1$ \\
\hline 440 & 5 & 131 & 0.98 & 11.3 & 86 & $23.3 \pm 0.1$ & $7.8 \pm 1$ & $243 \pm 0.6$ \\
\hline 440 & 7.5 & 89 & 1.45 & 11.4 & 128 & $23.4 \pm 0.1$ & $5.6 \pm 0.6$ & $240 \pm 0.6$ \\
\hline 440 & 10 & 66 & 1.93 & 11.3 & 171 & $23.5 \pm 0.1$ & $4.2 \pm 0.4$ & $238 \pm 0.6$ \\
\hline 630 & 2.5 & 237 & 1.09 & 16.1 & 68 & $33.4 \pm 0.2$ & $20.0 \pm 2$ & $269 \pm 0.7$ \\
\hline 630 & 5 & 122 & 2.18 & 16.3 & 133 & $33.8 \pm 0.1$ & $9.5 \pm 0.8$ & $262 \pm 0.5$ \\
\hline 630 & 7.5 & 82 & 3.24 & 16.3 & 199 & $34.0 \pm 0.1$ & $6.8 \pm 0.5$ & $259 \pm 0.6$ \\
\hline 630 & 10 & 63 & 4.29 & 16.4 & 261 & $34.1 \pm 0.1$ & $5.6 \pm 0.3$ & $257 \pm 0.6$ \\
\hline 830 & 2.5 & 224 & 1.86 & 20.4 & 91 & $42.6 \pm 0.3$ & $21.6 \pm 3$ & $287 \pm 0.8$ \\
\hline 830 & 5 & 115 & 3.73 & 20.7 & 180 & $43.4 \pm 0.1$ & $11.3 \pm 0.8$ & $279 \pm 0.6$ \\
\hline 830 & 7.5 & 77 & 5.56 & 20.7 & 269 & $43.6 \pm 0.1$ & $7.8 \pm 0.4$ & $275 \pm 0.6$ \\
\hline 830 & 10 & 59 & 7.39 & 20.9 & 353 & $43.8 \pm 0.1$ & $6.4 \pm 0.3$ & $273 \pm 0.7$ \\
\hline 1020 & 2.5 & 211 & 2.80 & 24.3 & 115 & $51.3 \pm 0.4$ & $23.9 \pm 3$ & $304 \pm 1$ \\
\hline 1020 & 5 & 108 & 5.59 & 24.6 & 227 & $52.1 \pm 0.1$ & $12.6 \pm 0.7$ & $295 \pm 0.7$ \\
\hline 1020 & 7.5 & 73 & 8.32 & 24.7 & 337 & $52.4 \pm 0.1$ & $8.9 \pm 0.4$ & $290 \pm 0.6$ \\
\hline 1020 & 10 & 56 & 11.06 & 24.9 & 445 & $52.6 \pm 0.1$ & $7.0 \pm 0.3$ & $288 \pm 0.7$ \\
\hline
\end{tabular}

A final consideration on data in Table 1 and Table 3: impedance measurements with an impedance meter (Wayne Kerr $6425)$ at medium signal $\left(\mathrm{V}_{\mathrm{ac}}=5 \mathrm{~V}\right)$ and at $20 \mathrm{~Hz}$ gave $\mathrm{C}=200 \mathrm{nF}$ for the MFCs and $\mathrm{C}=80 \mathrm{nF}$ for the large PZT sheet. In both cases, the agreement with the fitting parameters is acceptable.

\section{CONCLUSIONS}

Macro Fibre Composite (MFC) devices and bulk PZT sheets were characterised as energy harvesters to convert strain energy of the wing skin of an aircraft into electrical energy to power Wireless Sensor Nodes (WSNs). The devices were bonded to aeronautical grade Al-2024 alloy sheets and carbon fibre composite sheets and subjected to cyclic strain levels within a range of amplitudes they would be likely to experience as part of an aircraft wing.

All devices tested produced interesting levels of power, up to $12 \mathrm{~mW}$, with easily manageable output voltages in the broad range between 5 and $30 \mathrm{~V}$. The plots of voltage, current and power vs. electrical load present the same features for all devices, with the voltage rising towards the open-circuit value, the current decreasing progressively from the shortcircuit value and the power rising rather quickly up to the MPP and then slowly decreasing as the electrical load is further increased. Moreover, the voltage at the MPP for a given device is essentially only dependent on the strain applied, whilst the maximum power itself increases quadratically with strain and linearly with cycling frequency.

A comparison between the MFC and the bulk PZT harvesters highlights the higher power per unit device area in the bulk 
devices. Several factors have been identified as contributing to this observation: fibres in MFCs are slightly thinner and cover only $86 \%$ of active area and are separated from the strained substrate not only by the adhesive, as bulk PZT, but also by the kapton film that encapsulates them, with the result that strain is not as effectively transmitted to them from the substrate. Despite lower power generation, MFC may be preferable in critical applications because of the higher reliability intrinsic in their design. Comparison between large and small PZT sheets supports the prediction ${ }^{5}$ that edge effects reduce the efficiency of smaller devices.

The limited sizes of the devices investigated means that the Maximum Power Point (MPP) may occur at rather high value of impedance, which can be difficult to match on the power management unit. However, larger devices would have proportionally lower impedance. Several considerations suggest that larger devices are to be preferred: they produce more power, simply due to the larger area; they are more efficiently coupled to the substrate, with the reduction of losses due to edge effects; they have higher capacitance, hence lower impedance, which is advantageous for power extraction.

A comparison between results on the MFC on Al-2024 alloy and composite identified a lower power production in the former case; this hints to the possibility that the composite was more efficient in transferring its strain to the attached harvester due to the orientation of carbon fibres in the top layer. On the other hand, given the criticality of the adhesive thickness it is also possible that the observed differences stemmed from this latter factor. Extensive experiments on a larger number of samples would be needed to collect statistically significant comparison data.

Because of the important power generation of patch-like harvesters, it is clear that piezoelectric strain energy harvesting holds significant potential to power the wireless structural health monitoring systems needed to enable the new paradigm in through-life service engineering: predictive maintenance.

\section{ACKNOWLEDGEMENTS}

Part of this work was sponsored by the Cranfield's Innovative Manufacturing Research Centre (IMRC). The PZT sheets were kindly supplied by Jingdezhen Tonphin Electrical Co., Ltd - China.

\section{REFERENCES}

[1] Aronson, R. B., "What to Measure for Proper Maintenance," Manufacturing Engineering 129, 71-77 (2002)

[2] Phillips, P., Diston, D., and Starr, A., "Perspectives on the commercial development of landing gear health monitoring systems," Transportation Research Part C: Emerging Technologies 19, 1339-1352 (2011)

[3] Churchill, D. L. , Hamel, M. J. , Townsend, C. P., and Arms, S.W., "Strain Energy Harvesting for Wireless Sensor Networks," in Proceedings of SPIE 5055, 319-327 (2003)

[4] Smart Material, "Macro Fiber Composite (MFC) Datasheet," <http://www.smartmaterial.com/media/Datasheet/MFC-V2.0-2011-web.pdf>

[5] Pozzi, M., Guo, S., and Zhu, M., "Harvesting energy from the dynamic deformation of an aircraft wing under gust loading," Proceedings of SPIE 8348-110 (2012) 